\title{
EDITORIAL: Now We Are 10 and Occasional
}

When I first launched QAR in 1984, I really didn't think much about its long-term future. I simply wanted to produce a series which would cater for the publication of Queensland-based archaeological research, and especially the substantive material that so often became locked up in theses and reports, seldom to see wider publication. But now that Volume 10 is on my desk I have come to realise that it has served this purpose quite well over the years. The only disappointment to come from my association with this joumal is that it is no longer issued annually. As most subscribers will know, the decision to issue the journal occasionally after Volume 9 was forced upon me by a single and very simple fact - a dip in the submission of manuscripts over the past few years. This phenomenon was unexpected as it flew in the face of a steady increase of submissions since the 1984 launch. Furthermore, the slump continues despite numerous pleas and much cajoling of potential contributors, especially among the ranks of recent archaeology graduates with smoking-hot thesis results. Some such individuals of my acquaintance argued that they wanted to publish less substantive overviews in international journals before committing themselves to what they perceived as the 'boring' task of preparing descriptive manuscripts concerning the substance of the archaeological record. While some of these have achieved the first goal, few have yet published details of their research. One or two even gained employment on the strength of their international publications - and good for them! Others had very good intentions but never got around to writing anything for publication while a few, having gained their Honours BA degrees after a year of anxiety, were simply not interested in what they perceived as prolonging the agony and subsequently sloped off into the hills of obscurity beyond academe. Whatever the reason, the result is that QAR, a journal designed as a vehicle for site reports and other more descriptive and substantive information, has become occasional rather than annual.

I regard this matter of non-publication of substantive data, especially from theses, as a fairly serious issue in our discipline in Australia and cite several reasons why I regard it so. First, there is the problem of accessibility of theses. There was a time, some twenty or so years ago, when the archaeological community was so small and homogeneous that we had little trouble in keeping track of important $\mathrm{Ph} . \mathrm{D}$. and Honours BA research results. Furthermore, it was relatively easy and inexpensive to access the few theses being produced by our universities each year. It was simply a matter of contacting the authors and asking for a copy of their thesis, or at least permission to photocopy it. Today, this is no longer the case. As more and more theses are produced each year in line with the growth and diversification of our discipline, it is becoming increasingly difficult to keep abreast of this new knowledge in the traditional way. Furthermore, as the years pass and individuals for various reasons drop out of the archaeological community, it becomes increasingly difficult to track them down.

Second, while most of us realise that theses (and especially 4th-year BA theses) are usually far from perfect in terms of scholarship, organisation, and written expression, they often contain a considerable body of descriptive and quantitative information which is valuable for comparative research purposes. Unfortunately, journal editors normally want to publish general articles and do not accept a great deal of substantive data. Despite the sometimes highly touted interpretive conclusions of theses, when all is said and done, it is the descriptive information which forms the basis of such interpretations and it is this information which remains to be reinterpreted by future researchers. If it remains locked up in theses we as a community of scholars run the risk of missing out on valuable data. It is far better for the archaeological community that such information be published in a more accessible (and more scholarly) form. 
Thirdly, I raise a moral issue which was first brought to my attention many years ago while taking an introductory archaeology subject from Professor Jesse D. Jennings at the University of Utah. Jennings spent a considerable portion of one lecture to inform we incipient archaeologists of our obligations to the discipline. Of several points made, the one which particularly stuck in my mind was the obligation we have to the scientific community to present all our field and laboratory findings in a published form as soon as possible. Indeed, he was such a stickler on this point that before formal postgraduate degrees were awarded in archaeology, substantive material deriving from field-based thesis research had to be published. While not proposing that such a tough measure be taken in Australian universities, I do think that we should take appropriate steps to ensure that budding archaeologists (and some mature ones also) are reminded of this obligation to their discipline. The ways in which this can be accomplished are several and so obvious that I shall not take time to point them out here. Suffice it to say that, in my opinion, this obligation which has tended to be overlooked by many in the drive to publish in international journals, should be openly stressed more often.

Turning now to this $10^{\text {th }}$ anniversary volume, we celebrate the occasion by charging subscribers only $\$ 10$ ( $\$ 1$ for each year of the series). This is made possible in part by a change to a new printing firm which has significantly reduced production costs and in part by the growth of a small surplus in our budget over the past few years. I also take this opportunity to heartily thank the members of the QAR Editorial Board and others who have been involved in the refereeing process and who have contributed in numerous other ways over the years.

I end this piece with an invitation to all those with sites excavated but unpublished to send in your site reports, be they strictly Queensland-oriented or otherwise. I for my part pledge to attend to all submitted manuscripts without delay, so that they may be refereed and published as quickly as possible.

Jay Hall - Editor 